\title{
Literatura Afro-brasileira e suas interfaces
}

\author{
Elen Karla Sousa da Silva ${ }^{\mathrm{i}}$
}

\section{RESUMO}

Há contrários e adeptos no que se refere à classificação da Literatura Afrodescendente, Negra, Negro-brasileira ou Afro-brasileira. Essa contenda se estabelece quando os/as autores/as negros/as são evidenciados/as. Salientamos que os que se opõem à utilização das variadas terminologias argumentam que a especificação é problemática, pois insinua um julgamento ou uma estigmatização da literatura produzida por negros/as, acarretando dano ao reconhecimento dessa produção. Desse modo, apresentamos algumas reflexões sobre a Literatura Afro-Brasileira, a partir da escrita de Conceição Evaristo. No que concerne a esse conceito abordamos, preliminarmente, a perspectiva adotada por Zilá Bernd (1987; 1988a; 1988b; 2003), além de apresentar algumas considerações realizadas por pesquisadores/as e autores/as contemporâneos/as dedicados/as aos estudos de Literatura Afro-brasileira, como Cuti (2010; 2011), Eduardo de Assis Duarte (2008; 2010; 2011) e outros/as, elencados ao longo deste estudo.

Palavras-chave: Literatura Afro-Brasileira; Literatura Negro-brasileira; Autoria negra.

\begin{abstract}
Some people are in favor and against the classification of afro-descendant, black or AfroBrazilian literature. This feud is established when the black authors are evidenced. We point out that those who oppose the use of the different terminologies above-cited argue that the specification is problematic, as it implies a judgment or stigmatization of the literature produced by black people, causing damage to its recognition. Thus, we present some reflections on Afro-Brazilian Literature, from the writing of Conceição Evaristo. As far as Afro-Brazilian Literature is concerned, we first approach the perspective adopted by Zilá Bernd $(1987 ; 1988 ; 2003)$. We also present some considerations made by researchers and contemporary authors dedicated to the study of Afro-Brazilian literature, such as Cuti $(2010 ; 2011)$, Eduardo de Assis Duarte $(2008,2010 ; 2011)$ and others, listed throughout this study.
\end{abstract}

Keywords: Afro-Brazilian Literature; Black-Brazilian Literature; Black authorship.

\footnotetext{
${ }^{\text {i }}$ Doutoranda do Programa de Pós-Graduação em Letras da Universidade Federal do Rio Grande do Sul (UFRGS).

ORCID: https://orcid.org/0000-0003-3304-1469 | elenuema@gmail.com
} 


\section{LITERATURA AFRO-BRASILEIRA E CONCEIÇÃO EVARISTO: ALGUMAS REFLEXÕES}

A escolha por abordar reflexões sobre Literatura Afro-brasileira determina contextualizar e discutir não só os posicionamentos dos vários autores/pesquisadores, mas, igualmente, o uso das várias terminologias. Adotamos a terminologia Afrobrasileira, quando necessário na pesquisa, conectando-a ao texto literário brasileiro e à cultura, para assinalar um caráter identitário. Os adeptos da caracterização Literatura Afro, em contrapartida, intercedem pela visibilidade que o termo pode propiciar ao texto literário de autores/as descendentes de negros e negras.

Conforme Maria Nazareth Soares Fonseca (2011), a literatura feita por autores brancos não exige adjetivos em virtude de sua integração acentuada no cânone literário. De fato, os/as autores/as que formam o cânone possuem descendência de brancos e europeus, estando os/as autores/as negros/as em menor quantidade na tradição da literatura. Em referência à epígrafe inicial, segundo Abdias Nascimento (2011), os negros continuam excluídos e, em vista disso, é necessária uma caracterização, uma classificação. Deste modo, Nascimento (2011) posiciona a questão em uma prática transitória, contudo, inadiável.

Assim, a literatura brasileira vem ganhando distintos delineamentos, visto que diversos/as escritores/as se posicionaram a respeito de sua terminologia. No que concerne às obras literárias escritas e protagonizadas por negros/as, variadas nomenclaturas surgiram: Literatura Afrodescendente, Literatura Afro-brasileira, Literatura Negra ou Literatura Negro-brasileira, vocabulário adicionado por Cuti (2011).

Em relação a tais termos, observamos que alguns/mas críticos/as, estudiosos/as e pesquisadores/as se direcionam tanto para Literatura Afro-brasileira quanto para Literatura Negra. Autores como Cuti (2011) julgam que o termo Literatura Negra oferece mais conformidade com a realidade dos processos que geram o racismo no Brasil e que o emprego do prefixo "afro", por sua vez, transporta a marca do politicamente correto. Segundo o autor, o uso da expressão Literatura Afro-brasileira suaviza as questões raciais destacadas por essa literatura:

A palavra negro é muito mais polissêmica e contundente. Afro-brasileiro é um termo apaziguado de conflitos, lembra conceito forjado em gabinete. Muito 
menos rico que aquele. No Brasil, a ideologia da democracia racial prefere palavras mais amenas, que não tragam uma conotação conflituosa. Daí que, por detrás dessa similitude semântica, encontra-se uma guerra pela palavra, guerra sem testemunhas, em que Osman Lins alertava estar sempre empenhado o escritor. Veja, um afro-brasileiro não necessita ser necessariamente negro. Ele pode ser mestiço ou branco, o que em certa medida é o mesmo. A polarização criativa perde seu impulso, a crítica ao racismo também. A renúncia à branquitude perde o sentido. (CUTI, 2011, p. 60)

As questões tratadas por Cuti (2011) encaminham para reflexões sociológicas das expressões utilizadas na discussão de textos produzidos por autores/as negros/as, que propagam o tom polissêmico que essas terminologias transportam. À medida que Cuti destaca a semântica da terminologia Literatura Negra, Zilá Bernd (2011) opta por Literatura Afro-brasileira, considerado pela autora um recurso significante e, quiçá, mais adequado, pelo fato de conectar a literatura ao Brasil, à cultura, dando-lhe um caráter identitário.

Para Cuti (2010, p. 12), “[...] a literatura é poder, poder de convencimento, de alimentar o imaginário, fonte inspiradora do pensamento e da ação”. Durante bastante tempo, a literatura colaborou para a constituição de um imaginário negativo sobre o negro. Esse campo não é mera representação social, mas dialoga com a sociedade, transformando-a. Evidenciamos a natureza militante da literatura negra, que há séculos vem sendo estabelecida na perspectiva de anular o âmbito de subalternidade e de segregação que restringe o negro em nossa sociedade. Ainda para Cuti (2010, p. 12), a literatura "precisa de forte antídoto contra o racismo nela entranhado". Notadamente, os que experienciaram os infortúnios, as desgraças e as adversidades conduzem a ação de elaborá-la. De tal modo, Cuti (2010, p. 13) afirma que “os autores nacionais, principalmente os negro-brasileiros, lançaram-se a esse empenho, não por ouvir dizer, mas por sentir, por terem experimentado a discriminação em seu aprendizado”.

Lima Barreto, um dos mais expressivos escritores brasileiros, filho de exescravos, descrevia-se como um sujeito sociável, conversava com todas as pessoas de condições e classes e, desse modo, toda a sua produção é escrita com uma perspectiva do morador de subúrbio, do intelectual mulato e pobre que convivia com a população sofrida, ao mesmo tempo em que dá voz a uma fala que precisou de bastante tempo para se impor. Lima Barreto se irritava diante de exibições de riqueza e se comovia diante dos habitantes do subúrbio que iam descalços enterrar seus mortos. Romancista, cronista e contista, cidadão que garantiu aos seus contemporâneos que a vida havia de ser um protesto eterno 
contra todas as injustiças, reagiu com escárnio à elite hipócrita brasileira, considerada por ele preconceituosa. Nesse sentido, Manoel Freire (2014) diz que:

\begin{abstract}
Não se deve esquecer, entretanto, que o fato de Lima Barreto muitas vezes encarar a literatura menos como arte e mais como exercício de análise da sociedade e estudo da condição humana deve-se, sobretudo, a sua deliberada opção por uma literatura militante, na qual pudesse tratar com "absoluta sinceridade" os problemas que afligiam a sociedade de seu tempo, os quais o afetavam diretamente. (FREIRE, 2014, p. 87)
\end{abstract}

Enfatizamos que Lima Barreto assumiu um posicionamento crítico, irônico, combativo, e sua contribuição para a literatura brasileira é inquestionável, assim como para a Literatura Afro-Brasileira. Para Octávio Ianni (1988), Lima Barreto assumiu, em suas obras, "a problemática do negro de modo aberto, pleno, em suas dimensões humanas, sociais, culturais e artísticas" (IANNI, 1988, p. 6). O desejo por apresentar os que estão às margens da sociedade incitou a escrita do ficcionista, colaborando, portanto, para uma visão mais respeitosa sobre o negro: um enfoque que representava, de modo adequado, a condição a que estava submetido o sujeito pobre e negro no período pós-abolição. Ianni (1988) assevera que é nesse contexto que o negro passa a ocupar o não-lugar na sociedade: "lumpenizado no lugar de livre; proletarizado em condições adversas, em face das vantagens e dos favores concedidos por fazendeiros e governadores aos imigrantes; discriminado em termos sociais, econômicos, políticos e culturais" (IANNI, 1988, p. 5).

Em contraste ao poder hegemônico, e ciente de sua cultura, produziu uma literatura engajada, militante. A sua irritação crescia diante dos comportamentos e regras racistas de uma sociedade injusta. Segundo Freire (2014), a obra Diário íntimo, de Lima Barreto, forma um "repositório de confidências íntimas", na qual o autor despejou suas angústias e amarguras advindas, sobretudo, da segregação social. O Diário íntimo:

[...] serve de roteiro para se penetrar nas três dimensões fundamentais da sua escrita: a dimensão intelectual, que compreende tanto os projetos literários como a visão de mundo do escritor; a dimensão biográfica, na qual se revela um homem revoltado em face das injustiças sociais que atingiam a maior parte da população brasileira, inclusive ele próprio, também vítima da ordem excludente. (FREIRE, 2014, p. 88)

Em linhas gerais, por volta de 1970, no Brasil, principiaram-se discussões sobre como denominar a literatura marcada por um "eu enunciador" que se admite negro, assumindo uma identificação com a origem africana. Nesse período, passou-se a aceitar 
a terminologia Literatura Negra e, somente por volta do século XXI, ocorreu a estabilização do uso das nomenclaturas afro-brasileiro e afrodescendente, posto que a expressão "negro" poderia sugerir a epidermização do conceito, ou seja, a definição de uma expressão artística pela cor da pele dos escritores. Conforme Sueli Meira Liebig (2003, p. 21), "afro-brasileiro é o termo politicamente correto para designar a pessoa da chamada 'raça negra', nascida em nosso país". Ao listar as principais obras teóricocríticas e antologias, com publicação a partir de 1980, sobre essa literatura, afirmamos que no transcorrer do tempo ocorreu substituição na expressão Literatura Negra por Literatura Afro-brasileira; contudo, ressaltamos que ambas as designações coexistem.

Para compreendermos as proposições da Literatura Afro-brasileira, é necessário pensar sobre o porquê de uma literatura "afro-brasileira", porquanto os negros foram por bastante tempo apresentados pelo cânone, através de autores que denunciavam as péssimas condições escravistas em meados do século XIX. O escasso espaço concedido ao povo negro e à sua cultura na literatura canônica não elimina tal produção. Porém, o modo como o negro foi assinalado nestas produções, frequentemente, foi caricatural, reprimido, como um artefato inanimado, sem voz, encarcerado em estereótipos, sentenciado a uma escravidão literária.

Joaquim Manuel de Macedo, na obra Vítimas Algozes, publicada em 1869, apresenta o personagem Simeão (escravo) do seguinte modo:

[...] crioulo mimoso, perdido, malcriado pelas afetuosas condescendências e fraquezas dos senhores em casa, pervertido pelos deboches da venda e pelo veneno do crápula, ingrato pela condição de escravo, sem educação e sem hábito de trabalho, contando com a liberdade e não conseguindo era um perverso armando loucamente contra os seus senhores pelas mãos de seus senhores. (MACEDO, 2010, p. 49)

Alguns escritores não deram importância à presença de povos de ascendência africana em seus escritos, ou apresentavam essas personagens de forma estereotipada, assim como no fragmento anterior, no qual percebemos a descrição do escravo como um pervertido, cruel, pérfido, de maneira a demonizá-lo, expondo-o como vilão. Lamentavelmente, inúmeras marcas foram construídas e são reiteradas em narrativas na contemporaneidade. 
Entre as diversas vertentes marginalizadas pelo cânone, a Literatura AfroBrasileira se faz presente mediante o engajamento de autores/as negros/as. Compreendemos, não obstante, que os empenhos para o reconhecimento da produção literária negra, comprometida etnograficamente ou não com a identidade étnica afrodescendente, através do cânone nacional, possui suas raízes previamente à abolição da escravatura. Podemos atribuir o fato dessa literatura ainda não ter se consolidado no meio canônico a alguns princípios que colaboram para o seu entrave, pois o cânone constitui-se como:

[...] um conjunto de textos que passou pelo teste do tempo e que foi institucionalizado pela educação e pela crítica como clássicos, dentro de uma tradição, vem a ser o pólo irradiador dos paradigmas do quê e do como se escreve, do quê e do como se lê. Tradicionalmente, a sua constituição está pautada no processo de reprodução do mesmo, pois a força homogeneizadora que atua sobre a seleção reafirma as identidades e afinidades e exclui, portanto, as diferenças, posto que essas são incompatíveis com um todo que se quer uniforme e coerente em termos de padrões estéticos de excelência, argumento geralmente invocado na ratificação do estatuto canônico de uma obra. (SCHMIDT, 1996, p. 116)

O percurso do negro brasileiro na literatura é caracterizado primeiramente por uma narrativa descritiva, em que sobressaem minúcias sobre a vivência, religiões, hábitos e crendices. A partir do século XIX, surgem os primeiros manifestos autênticos em combate à escravidão, divulgados em jornais. Cruz e Sousa, Lima Barreto e Luiz Gama expressaram em suas obras o incômodo em relação ao preconceito racial. Entre os séculos XIX e XX, esse engajamento era solitário, sem nenhuma organização com a mesma finalidade. Conforme Cuti (2010):

Luiz Gama e Cruz e Souza atuaram em prol da abolição da escravatura ao lado
de brancos liberais. Lima Barreto aproximou-se de correntes de esquerda que
iniciavam suas atividades no Brasil. Entretanto, do ponto de vista literário,
foram solitários, em especial no empenho de sua afirmação racial ou crítica ao
racismo [...] com base em suas experiências de serem racialmente
discriminados, desenvolveram textos nos quais deixaram transparecer um
posicionamento diferente pela constituição de um sujeito étnico negro. (CUTI,
2010, p. 63)

Luiz Gama nasceu em Salvador e conseguiu ser alfabetizado após os 17 anos de idade. Intelectual autodidata, foi um dos grandes abolicionistas do país, considerado o primeiro poeta a assumir a etnia negra em sua escrita, no século XIX, e foi um 
abolicionista que fez uso da intelectualidade para a libertação de negros escravizados. Gama foi escravizado e conseguiu superar essa condição social praticamente intransponível. Em seu livro de poemas Primeiras Trovas Burlescas de Getulino, publicado em 1859, o autor satirizava a nobreza da época e, no período em que se estabelecia uma brasilidade constituída principalmente pelo indianismo ufanista, de modo lírico e satírico, escreveu com base no ponto de vista de um sujeito negro.

No mesmo período de Primeiras Trovas Burlescas, de Gama, foi publicada a narrativa abolicionista Úrsula, primeiro romance de autoria afrodescendente, da romancista maranhense Maria Firmina dos Reis, esquecida por bastante tempo no cânone da literatura brasileira. É a escrita de uma mulher nordestina e negra que põe em questão as amarguras do negro escravizado; ademais, a escritora se situa em prol de um Brasil sem preconceitos, cujas diferenças de raça, gênero e classe não constituam distinção no âmbito social.

Outro exemplo a mencionar diz respeito a Joaquim Maria Machado de Assis, uma figura exponencial da literatura de língua portuguesa em todos os países. Juntamente com Lima Barreto, Cruz e Sousa e Maria Firmina dos Reis, forma o grupo de precursores da literatura negra. Machado de Assis sempre se opôs à escravidão, entretanto, existia um acanhamento quanto ao emprego de uma escrita panfletária no texto literário. Contudo, em alguns textos, protegia-se utilizando pseudônimos. É fato que parte da crítica brasileira considera o escritor alienado aos problemas sociais de seu período, principalmente em relação à condição escravista dos afro-brasileiros, que persistiu no decorrer de sua existência.

Não há herói branco e nem negro na produção de Machado de Assis, visto que seus textos são anti-heroicos, antiépicos. Brás Cubas, por exemplo, é um canalha; Bentinho é um derrotado, e o mais incrível é que temos um senhor de escravos que está morto. Brás Cubas se encontra morto já na primeira página do livro, e o autor não o enterra; faz esse defunto jogar os podres dessa classe escravista dominante ao longo de toda a narrativa $\mathrm{O}$ mais inacreditável é que o livro foi publicado primeiro na Revista Brasileira, apresentado em formato de folhetim, em pequenos capítulos; ou seja, esse defunto entrava todos os domingos nas casas dos senhores de escravos. Isso em 1880, oito anos antes da abolição, embora o grande livro desse processo político e social, Abolicionismo, de Joaquim Nabuco, seja de 1883, três anos depois. Machado de Assis é 
precursor em vários sentidos e, ao invés de fazer uma literatura panfletária, de palanque, ele usa a ironia.

É importante enfatizar que encontramos a negritude do referido autor mais evidente nos contos e crônicas. Alguns biógrafos e pesquisadores o acusam de branqueamento, aburguesamento e completa omissão política diante das tragédias sociais de sua época, como a escravidão. Porém, os estudiosos admitem esse posicionamento exatamente porque têm como base de suas pesquisas a presença inexpressiva dos negros em suas narrativas. Na posição de mestiço, escritor e funcionário público, não seria sensato expor uma crítica aberta à burguesia, sobretudo em um amplo relato. É difícil saber qual seria o público leitor do autor em estudo, entretanto, supostamente poderiam ser componentes da categoria elitista, escravista, senhorial e branca. E, consequentemente, em suas narrativas, com enorme volume de laudas, seria complexo abordar assuntos referentes à sua afrodescendência.

Conforme Nei Lopes (2006), no Dicionário Escolar Afro-Brasileiro, Machado de Assis inicia, aos quinze anos de idade na literatura, pelas mãos do também afro-brasileiro e editor Paula Brito, principiando um caminho próspero de escritor e jornalista. Não foi possuidor de escravos, não era descendente de burgueses, nem rico, mas sim um servidor que, pelo merecimento de sua obra, convivia de forma igualitária com a fidalguia do império. Em crônicas, narra que no dia 13 de maio comemorou, nas ruas, a abolição.

No campo do discurso literário do século XIX, o desprezo à cultura africana era exposto por escritores que teoricamente eram a favor da abolição da escravatura ${ }^{1}$. O homem negro era frequentemente apresentado estereotipado, através de características negativas, segundo aponta Duarte (2007):

[...] os estereótipos do escravo vingativo e assassino, do feiticeiro deformado física e moralmente, ou da mucama pervertida que destrói a família do senhor, estão presentes em Vítimas e algozes, de Joaquim Manoel de Macedo; já a mulata assanhada, que seduz e leva o português à perdição, destaca-se nas páginas de $\mathrm{O}$ cortiço, de Aluízio Azevedo; e o negro de alma branca, reduzido a cão fiel ao senhor, ajuda a compor a figura do preto Domingos, personagem de José do Patrocínio em Mota Coqueiro ${ }^{2}$ [...]. (DUARTE, 2007, p. 251-252)

Em Memórias Póstumas de Brás Cubas (1881), uma situação ligada à escravidão se refere aos momentos em que se aborda o tráfico negreiro, por meio de um jantar que a família de Brás Cubas organizou, em 1814, para celebrar a destituição de Napoleão: 
As moças falavam das modinhas que haviam de cantar ao cravo, e do minuete e do solo inglês; nem faltava matrona que prometesse bailar um oitavado de compasso, só para mostrar como folgara nos seus bons tempos de criança. Um sujeito, ao pé de mim, dava a outro notícia recente dos negros novos, que estavam a vir, segundo cartas que recebera de Luanda, uma carta em que o sobrinho lhe dizia ter já negociado cerca de quarenta cabeças, e outra carta em que... trazia-as justamente na algibeira, mas não as podia ler naquela ocasião. O que afiançava é que podíamos contar, só nessa viagem, uns cento e vinte negros, pelo menos. (ASSIS, 1994, p. 530)

Através da lembrança desse fato da infância de Brás Cubas, percebe-se que o tráfico de escravos era um tema banal na reunião social organizada por sua família. Os escravos compunham um produto comercial como outro qualquer. Oriundos de Luanda, eram calculados pelo número de cabeças, como se fossem rebanho, e se vê o regozijo do submisso, por virem, só nessa viagem, pelo menos cento e vinte negros.

Desde o início da escravidão, em 1531, o negro tem sido importante personagem na literatura brasileira, especificamente no século XIX; nesse período, nem sempre encontramos a representação fiel e equilibrada da vida do negro nos romances. De modo geral, na literatura brasileira, encontramos a representação do negro também nas produções de José Lins do Rego, Graça Aranha, Coelho Neto, José Américo de Almeida, Rachel de Queiroz, Jorge de Lima, Jorge Amado, Érico Veríssimo, entre outros.

Conforme estudos empreendidos por distintos teóricos sobre a especificidade dessa vertente da literatura brasileira, observamos questionamentos sobre a Literatura Negra ou Literatura Afro-brasileira se apresentar como uma tendência da Literatura Brasileira e, por vezes, a não anuência da hipótese de haver uma literatura afro-brasileira. Todavia, tal literatura é factual desde a constituição de nossas letras nacionais. Segundo Duarte (2010), essa literatura se presentifica desde a Era Colonial. Contudo, a escrita afro-brasileira é fundamentada por elementos que a diferenciam do conjunto de textos da nossa pátria. É precisamente essa questão que é discutida por Duarte (2008), fundador do site Literafro $^{3}$, no texto Literatura afro-brasileira: um conceito em construção. $\mathrm{O}$ autor propõe alguns critérios para a adoção da denominação literatura afrobrasileira, que são: a temática, o ponto de vista, a autoria, a linguagem e o público leitor.

[...] a temática: - o negro é o tema principal da literatura negra, afirma Octavio Ianni, que vê o sujeito afro-descendente não apenas no plano do indivíduo, mas como - universo humano, social, cultural e artístico de que se nutre essa literatura. Em segundo lugar, a autoria. Ou seja, uma escrita proveniente de 
autor afro-brasileiro, e, neste caso, há que se atentar para a abertura implícita ao sentido da expressão, a fim de abarcar as individualidades muitas vezes fraturadas oriundas do processo miscigenador. Complementando esse segundo elemento, logo se impõe um terceiro, qual seja, o ponto de vista. Com efeito, não basta ser afro-descendente ou simplesmente utilizar-se do tema. É necessária a assunção de uma perspectiva e, mesmo, de uma visão de mundo identificada à história, à cultura, logo, a toda problemática inerente à vida desse importante segmento da população. (DUARTE, 2008, p. 12)

Enfatiza-se que nenhum desses elementos isolados favorece a vinculação à Literatura Afro-Brasileira e, sim, a sua interação. Desse modo, o pesquisador elege a denominação "afro-brasileira", estabelecendo relação com a cor da pele, enquanto “tradução textual”. Através do diálogo entre a temática, autoria, ponto de vista, linguagem e público, percebe-se a presença da Literatura Afro-brasileira em sua primazia. Portanto, ratificando, a Literatura Afro-brasileira é um conceito em devir, isto é, em discussão, conforme nos alerta Duarte (2008). Comprova-se a grandeza de textos aglomerados, inclusos ou não na história da literatura. É uma produção racional, lúcida, que explicita de inúmeros modos o otimismo do ser negro, a mulher, o homem, festeja as divindades, os ancestrais, percorre os espaços da história, possuindo caráter marginal e, sobretudo, denuncia o preconceito e a discriminação.

De acordo com Luiza Lobo, em Crítica sem Juízo (2007), a Literatura Afrobrasileira atual é repleta da "forma confessional" de uma escritura de "perfil existencial" e que anseia por uma reconstrução da história do negro no Brasil. Desse modo, possui uma simbologia, uma particularidade e uma linguagem própria. A autora ainda argumenta que "só pode ser considerada literatura afro-brasileira [...] aquela criada por afrodescendentes que assumem ideologicamente sua identidade" (LOBO, 2007, p. 340).

Lobo não restringe a Literatura Afro-brasileira a uma escrita puramente ideológica, política e não literária, o que a colocaria à margem da crítica estética de textualidade. O que se festeja é a criação de:

condições para seu desenvolvimento. Está no mesmo caso a literatura de autoria feminina. $\mathrm{O}$ critério estético, portanto, tem de ser posterior à própria afirmação da literatura afro, sob pena de, em caso contrário, agir como filtro repressor a sua produção. (LOBO, 2007, p. 340)

A autora prossegue:

Focalizando a literatura afro que surgiu desde a década de 1970 como uma possibilidade de releitura cultural, percebe-se que, nesta fase, não importa sua 
qualidade, mas sim sua oportunidade. Noutros termos, até o momento, é o movimento ideológico que ele carrega para as consciências que torna um documento importante, para além dos estereótipos e independe de sua qualidade. É o próprio sintoma de sua emergência que altera a dialética do corpo da linguagem, que passa a expressar uma nova mensagem, pois inverte a ordem do colonizador e introduz novos parâmetros na discussão da cultura nacional. (LOBO, 2007, p. 268)

Luiza Lobo (2007) também opta pela designação "literatura afro-brasileira”, já que tal artifício é necessário para "arrancar a literatura afro-brasileira do seu reduto dentro da literatura em geral, que a trata como tema folclórico, exótico, ou como estereótipo, é preciso que ela seja feita, efetivamente, pelos afro-brasileiros" (LOBO, 2007, p. 331). De tal modo, a concepção de literatura afro-brasileira se relaciona à existência, no Brasil, de uma conexão entre textos, estabelecida por uma perspectiva negra de enxergar e perceber o mundo, comunicado por uma fala caracterizada, tanto na opção do nível lexical quanto no nível dos símbolos empregados ou da constituição do imaginário e pelo anseio de readquirir memórias perdidas.

Isso posto, a Literatura Afro-brasileira ou Negra, na escolha de grande número de poetas, é negra por exprimir a vivência comum da tirania e de discriminações sofridas por um grupo que deseja manifestar integralmente sua subjetividade. Elimina-se, assim, uma poética tradicional que dominava na literatura brasileira, em que o negro era o Outro, era artefato, mencionado na terceira pessoa do discurso, isto é, aquele de quem se fala, para passar a sujeito da enunciação (aquele que fala em primeira pessoa do singular ou do plural), à proporção que o autor se põe como porta-voz do grupo no qual está inserido.

Segundo Lobo (2007), a inserção no conceito de Literatura Afro-brasileira de produções de escritores brancos ou sem um reconhecimento de pertencimento étnico ecoa como a não valorização da literatura afro, uma vez que:

retirar da literatura afro o traço da negritude é novamente misturá-la na produção geral em que se confundirá com a imensa quantidade de obras de autores brancos que falam sobre negros, quer vendo-o sob o ângulo dos estereótipos de modo consciente, quer de modo inconsciente. (LOBO, 2007, p. 328)

Zilá Bernd (1987) põe em discussão a ideia sobre o que principiou a ser designado Literatura Negra no Brasil, a partir da ocasião em que os autores afrobrasileiros assumiram e organizaram uma postura individualizada na exposição dos textos literários produzidos por eles. Bernd (1987) posiciona-se sobre uma questão que várias 
vezes é utilizada como premissa contrária à proposição de estudo e exposição dessa produção literária: o encadeamento entre texto e raça. Para a autora, a literatura que principiava a se sustentar com base em um mesmo passado histórico ligado à origem afrodescendente não se ilustraria unicamente pela "epidermização do texto", isto é, o aglomerado de textos que se intitulava Literatura Negra se relacionava ao que, conforme a autora, Leon François Hoffmann nomeou de "articulação de uma reivindicação": os escritores compartilham de uma perspectiva semelhante ao expressarem a realidade, forma essa arrolada ao fato histórico de se constituírem afrodescendentes, de entenderem as marcas de uma escravização ancestral e de perceberem a necessidade da importância de sua contribuição cultural e política no centro do todo que compomos.

Por conseguinte, a literatura afro-brasileira aparece para modificar o status de sujeição do branco contra o negro no discurso literário, pois, antes, os predicados do negro, em seu perfil, professavam estereótipos; a título de exemplificação, podemos citar a pele, o cabelo, o passado escravista, entre outros. Todavia, através das obras produzidas por negros e mulatos, ocorreu uma ressignificação desses traços, antes negativos, de modo que a beleza e estética do negro passam a ser apreciadas, sua cultura e história ressignificadas, pondo em questão a "cultura" e estética da supremacia branca:

\footnotetext{
Tendo sua gênese na rebelião, na insurgência contra a situação vigente, a literatura negra configura-se como uma forma privilegiada de autoconhecimento e de reconstrução de uma imagem positiva do negro. Nesta medida, o conceito de literatura negra emerge da própria característica dos signos: a de estarem em um permanente movimento de rotação, onde os signos que nos exilam podem vir a ser os mesmos que nos constituem na dimensão humana. O surgimento do que chamamos de literatura negra está, pois, relacionado com a compreensão desta rotatividade, isto é, com a compreensão de que um mesmo signo - NEGRO - pode remeter à ofensa e à humilhação, mas também pode ser assumido com orgulho. (BERND, 1988b, p. 95-96)
}

Ademais, há escritores que inserem uma impressão negra bem acentuada, de tal modo que, no universo da escrita, o negro passa a ter o propósito de se autoexaltar como sujeito, reinventando a si próprio. Bernd (1988b) nos auxilia a entender essa questão:

[...] a presença de uma articulação entre textos, determinada por um certo modo negro de ver e de sentir o mundo, e a utilização de uma linguagem marcada, tanto no nível do vocabulário quanto no dos símbolos, pelo empenho em resgatar uma memória negra esquecida legitimam uma escritura negra vocacionada a proceder a desconstrução do mundo nomeado pelo branco e a erigir sua própria cosmogonia. Logo, uma literatura cujos valores fundadores repousam sobre a ruptura com contratos de fala e de escritura ditados pelo 
mundo branco e sobre a busca de novas formas de expressão dentro do contexto literário brasileiro. (BERND, 1988b, p. 22)

A literatura afro-brasileira ou negra contribui para a construção de uma identidade negra, assume a função de protesto em oposição às complexas e tênues formas de segregacionismo que persistem na coletividade, que ainda enxergam nos descendentes de africanos os sinais das centenas de anos de escravização, possuindo uma tendência de construir-se bastante próxima destes indicativos, deixando, ocasionalmente, sua energia poética. A literatura negra possui uma propensão a tomar partido dos direitos de igualdade dos negros no Brasil. Ao levantar esta bandeira em favor dos direitos humanos e ao construir textos com tons de revolta e denúncia, esta literatura pode pôr em perigo sua literariedade, podendo se tornar o lugar-comum de representações estereotipadas.

Como se evidencia nas palavras da pesquisadora Bernd (1992), o que efetivamente define a existência de uma literatura negra é o discurso, com o surgimento de um "eu enunciador" que se quer negro. Essa constituiria a principal distinção entre os demais autores, que somente usam o negro como tema. Conforme a autora, seria o critério presumível para conceituar a escrita negra como componente-chave que diferencia essas produções:

[...] como uma espécie de divisor de águas entre um discurso sobre o negro, que sempre existiu na literatura brasileira, e um discurso do negro que corresponde ao desejo de renovar a representação convencional constituída ao longo dos séculos, quase sempre carregada de preconceitos e de estereótipos. (BERND, 1992, p. 267-276)

Sob tal perspectiva, podemos definir a literatura negra brasileira como aquela que surge de uma consciência negra, isto é, em que um "eu” enunciador adquire uma identidade negra, no anseio de reconquistar as raízes culturais afro-brasileiras e uma literatura de protesto contra a discriminação da qual é vítima o povo negro brasileiro, embora transcorridos mais de cem anos da abolição da escravatura. Bernd (1987) reflete sobre identidade com seu desenvolvimento ligado à ideia de alteridade, no processo de construção e desconstrução identitária na relação com a diferença; nas palavras da autora: "Esta consciência da diferença para o negro brasileiro é o elemento sobre o qual se funda um projeto de superação da sua marginalidade histórica” (BERND, 1987, p. 38).

Zilá Bernd (1988b, p. 48) questiona “que fator será o determinante da fissura da 
qual se pode falar em literatura negra e não apenas em temática da escravidão?” E diz: "que esse demarcador de fronteiras é o surgimento de um sujeito de enunciação no discurso poético, revelador de um processo de conscientização de ser negro entre brancos". Essa afirmativa ratifica que não é apenas a tonalidade da pele do/a escritor/a que definirá e situará a sua produção como Literatura Negra, mas inclui-se também o seu posicionamento ideológico e o modo como ele/a encara a condição de ser um/a escritor/a afrodescendente.

Ademais, Bernd (1987) já expunha angústia com o escasso interesse de algumas academias no que diz respeito à análise da produção literária dos/as escritores/as afrobrasileiros/as. Atualmente, partilha-se a mesma angústia, pois, apesar de a discussão e o estudo sobre a afrodescendência terem evoluído muito, principalmente nas áreas da história, antropologia e sociologia, ainda há o que se realizar na área literária. Grande parte dos estudos mencionados pela autora abordam a imagem do negro na produção de escritores reconhecidos na historiografia literária brasileira ou a propósito de questões referentes à conceituação da negritude ou identidade negra na literatura, e não a respeito dos textos literários de autores afro-brasileiros contemporâneos, e sequer sobre autoras afro-brasileiras.

Conforme Bernd (2002, p. 36), em seu texto Enraizamento e Errância: duas faces da questão identitária, o texto literário "pode ser um poderoso agente ou pelo menos um excelente coadjuvante quando se trata de construção, expressão e solidificação de diferentes coletividades ou de grupo etnoculturais". Tais escritores têm no ato literário um "processo de construção e expressão de identidades", as quais se evidenciam no cerne dos questionamentos, através de um incompleto jogo de "desmontagem de linguagens e de discursos".

Encontramos significativas pesquisas sobre a produção e estilo dos escritores afrobrasileiros partindo, sobretudo, daqueles que iniciaram a divulgação de seus textos nos “Cadernos Negros". No site Literafro que, como já mencionado, é decorrente do seu grupo de pesquisa, Duarte (2008) reúne artigos de diversos pesquisadores que têm se esforçado para analisar essa produção, além de textos sobre os mais valorosos autores da crescente Literatura Afro-brasileira.

A Literatura Afro-brasileira possui traços e características singulares. Há uma literatura autodeclarada negra, de combate ao racismo, lugar de denúncia, de resistência 
dos negros; ademais, têm-se o/a autor/a negro/a, o assunto negro, um ponto de vista negro, uma linguagem que busca traduzir esse ponto de vista e, principalmente, uma obra escrita para o público negro. É uma característica mais contemporânea dos últimos trinta a quarenta anos, quando o Movimento Negro (após a ditadura) cresce no Brasil.

Ao refletir a respeito da expressão Literatura Negra, é conveniente mencionar o movimento do Renascimento Negro (1920) e da Negritude (1934). Munanga, em seu livro Negritude, Usos e Sentidos (2012), cita as diversas acepções do vocábulo "negritude", entre os quais expõe o sentido cultural, por exemplo, a afirmação do sujeito negro pelo reconhecimento de sua cultura, iniciando pela poética. No que concerne aos movimentos, ambos transmitem a participação da Literatura Negra no panorama mundial. O Renascimento Negro surgiu nos Estados Unidos, enalteceu o negro, rebatendo os rótulos e intolerâncias referentes à cor da pele; o Movimento da Negritude foi concebido na França, exaltando os valores culturais africanos, até aquele momento, marginalizados. Conforme Domingues (2005, p. 4), os intelectuais participantes do movimento argumentam que o sujeito deveria reconhecer a sua ascendência racial. Concomitantemente, proclamavam a liberdade de estilo, da configuração e da imaginação face aos padrões da literatura francesa.

Vale salientar que, nos dias atuais, de certo modo, o negro, a despeito das desventuras, tem inquirido esta "sentença" e batalhado pela concreta afirmação identitária negra. A cada dia as máscaras brancas são negadas e o negro evoca o seu negrume, sem o temor dos julgamentos da chamada sociedade hegemônica. Segundo Fanon (2008), o complexo de inferioridade passa pela cor da pele; possui uma triagem social, existe e somente será combatido quando o negro adquire noção das realidades sociais e econômicas; segundo Munanga (2012), aceitando-se:

o negro se afirma cultural, moral, física e psiquicamente. Ele se reivindica com paixão, a mesma que o fazia admirar e assimilar o branco. Ele assumirá a cor negada e verá nela traços de beleza e de feiura como qualquer ser humano “normal”. (MUNANGA, 2012, p. 43)

Para Bernd (1988a), a Negritude ocasionou para o Brasil "a reversão de valores", transformando em positivo o que era negativo:

Ao enumerar características físicas (carapinha, pixaim, lábios grossos, cor da pele etc.), o poeta ${ }^{4}$ inverte sua simbologia, elevando à categoria de símbolos 
positivos o que, na visada da cultura branca ocidental, fora minorizado e impregnado de conotações negativas. (BERND, 1988a, p. 150)

Destarte, no Brasil, as influências da Negritude colaboram e marcam as concepções da Literatura Negra. Tais fatos corroboram a caracterização da literatura brasileira, favorecendo reflexões sobre a participação do negro na escrita literária no Brasil.

Em inúmeros volumes, a questão da designação da produção de mestiços e negros no Brasil está presente na inquietude de concluir a contenda na escolha de uma nomenclatura. Os dilemas quanto à melhor definição de uma literatura que se relaciona com as indagações sobre raça/etnia fazem parte de um processo relevante e expressivo que tem, na literatura, um solo fecundo de significação.

Florentina Souza (2005) analisou a história, o conteúdo e os objetivos, assim como a perspectiva política e literária da produção de autoria negra no Brasil, no século $\mathrm{XX}$, publicada nos "Cadernos Negros" e no "Jornal do Movimento Negro Unificado" (MNU). Conforme a pesquisa, abrangendo os textos de ambos os grupos de publicações, com autores/as de distintos estilos e linguagens, ambos acabam por formar "um mosaico que tenta sustentar sua identidade no propósito comum de posicionar-se contra o racismo" (SOUZA, 2005, p. 14).

Souza (2005) atenta para a questão de que essas publicações iniciam por volta de 1978 e 1981 e que, nesta ocasião, desenvolvia-se um diálogo íntimo entre marxismo e literatura. Logo no início da década seguinte, esse cenário de influência altera-se e principia a notar-se no pensamento contemporâneo um maior entendimento da identidade como uma camada móvel, estabelecida no interior da vida cultural. A pesquisadora menciona como sinal dessa percepção a adição do subtítulo "contos/poemas afrobrasileiros", em 1995, nos "Cadernos Negros", e compreende como estratégica a determinação de evidenciar a ascendência histórica dos escritores ali concentrados. Ao ressaltar essa origem, os escritores se declaram pertencentes ao grupo que, sendo afrodescendente, decide debater, na sua escrita, o lugar de pertencimento de uma perspectiva diversa da tradição em que foram instruídos. Para o grupo pertencente aos "Cadernos Negros", a reformulação da história de seus/as antepassados/as africanos/as e a revalorização da imagem e voz do/a afro-brasileiro/a são questões sempre atuais no que organizam como arte. Os/as escritores/as agrupados/as nos "Cadernos Negros" abarcam, 
como pretexto de inspiração da escrita literária, a denúncia e a percepção de circunstâncias prejudiciais à saúde, à cidadania e ao bem-estar emocional/físico do povo afrodescendente. Combatem, assim, em suas narrativas, ficções ou poemas, a invisibilidade e os modelos e estereótipos que abrangem os afrodescendentes em nossa cultura.

Os "Cadernos Negros" marcam decisivamente a ascendência da Literatura Afrodescendente, ocasionando uma maior visibilidade à autoria negra de pessoas como Lia Vieira, Lepê Correia, Mel Adún, Geni Guimarães, Raquel Garcia, Esmeralda Ribeiro, Cristiane Sobral, Fausto Antônio, Miriam Alves, Lande Onawale, Conceição Evaristo, entre outros. Autores/as, em seu maior número, excluídos/as do comércio editorial e da academia, que descobriram na coletividade a substancial ligação com o/a leitor/a. Temáticas como identidade étnica, diáspora, mulher negra, escravidão e herança cultural africana são rotineiras nas produções desses/as autores/as.

A autodefinição de negros/as brasileiros/as que estão inseridos/as na produção cultural em nosso país é relevante também, visto que uma das estratégias de invisibilização dos afrodescendentes surge da tradição do que os pesquisadores do tema chamam de artifícios de "branqueamento" dos afro-brasileiros que buscam atitudes de poder e/ou produção intelectual. Esse artifício se efetua por meio da afirmação inconsciente do/a próprio/a negro/a de que deve buscar reduzir as marcas étnicas e de comportamento de sua exterioridade e vida social que o/a atrelem a uma ancestralidade africana. Esse método corrobora o pensamento de que parte dessa população não estaria habilitada para papéis mais aprimorados. De tal modo, ao se apropriar de determinados papéis, a sociedade racista acredita que o afrodescendente possa "apagar os vínculos étnicos e os traços físicos, apagar a cor em situações determinadas [...]; seu grupo étnico é esquecido para registrar apenas a excepcionalidade da situação" (SOUZA, 2005, p. 36).

Além disso, ao não encontrar elementos de identificação e referência em cargos intelectuais e/ou que gozam de conceito e consideração social, o afrodescendente tende a abraçar a concepção de que, para elevar-se, necessita extinguir qualquer amarração com sua ascendência. É evidente que o reforço desse preconceito se concretiza pela ação de reprodução de estereótipos negativos, como a associação da imagem do homem negro à violência, à incapacidade intelectual, à volúpia excessiva e sua invisibilidade, entre outros. Na área das letras, há reverberações dessa prática, com a marginalização dos 
autores afrodescendentes, na ausência de espaço editorial e na insuficiência de estudos sobre esse conjunto de autores nas esferas acadêmicas.

Fanon (2008) nos apresenta que entre negros que têm uma posição social satisfatória, o conflito provocado pela discriminação pode camuflar-se por bastante tempo, não pelo fato de que não ocorra o racismo, mas porque o negro pode não encontrar identificação com sua ancestralidade e, dessa forma, continuar sem a percepção de que é alvo de alguma segregação, numa negação que não o resguarda mais fortemente das consequências psicológicas danosas, visto que, por determinado contexto extraordinário, necessite enfrentar tal situação. $O$ autor elucida a situação, aludindo ao panorama de suas experiências. Os antilhanos negros de classe média alta, quando precisavam migrar para a Europa para instruir-se, por exemplo, percebiam-se negros e alvos de racismo por parte dos europeus. Até esse momento, não tinham consciência da noção de inferioridade que continuamente associaram aos negros africanos. Essa nova concepção trouxe a Fanon (2008) o prisma do não lugar do negro em condição colonizada:

Eu era ao mesmo tempo responsável pelo meu corpo, responsável pela minha raça, responsável pelos meus ancestrais. Lancei sobre mim um olhar objetivo, minhas características étnicas [...] e então detonaram meu tímpano com o atraso mental, com as taras raciais, os negreiros e, sobretudo, com "y a bom banania"s. (FANON, 2008, p. 106)

A psicóloga Neusa Santos Souza (1983) pesquisou como evolui o processo de desenvolvimento emocional do negro na sociedade brasileira. Segundo a pesquisadora, o negro se desenvolve mergulhado em uma ideologia que lhe confere como positivos os valores, a história e os símbolos culturais eurocêntricos, opondo como inferiores e negativos os elementos, história, conduta e valores estéticos de ascendência africana. O afrodescendente se desenvolve sendo ensinado que sua aparência e sua ancestralidade não são boas, frustrando-se perante a impossibilidade de se tornar um indivíduo que valorize tal cultura. A maior agressão se lança quando, diante desse bloqueio, o sujeito fracassado conjectura como exclusiva opção, no intuito de ser aceito, a negação de si, dos seus ascendentes e da sua feição em um método de autoviolação. Sob tal ótica, configura-se uma procura neurótica, provocando ações de autoagressão constantes ao ser psíquico que se encontra em desenvolvimento. Souza (1983) expõe, em sua pesquisa, que o processo de ascensão social do afrodescendente no Brasil é geralmente análogo a um processo de 
insanidade, alienação de sua imagem étnica e do processo de branqueamento, no aspecto físico e na admissão de valores eurocêntricos:

\begin{abstract}
O negro que se empenha na conquista da ascensão social paga o preço do massacre mais ou menos dramático de sua identidade. Afastado de seus valores originais, representados fundamentalmente por sua herança religiosa, o negro tomou o branco como modelo de identificação, como única possibilidade de tornar-se gente. (SOUZA, 1983, p. 18)
\end{abstract}

Em Poesia negra no modernismo brasileiro (1988), Benedita Gouveia Damasceno expõe a dificuldade de definir "quem é negro no Brasil”, país que, por sua mestiçagem étnica e cultural, inseriu "crenças, línguas e hábitos" da cultura negra, fator que acentua "a consciência de uma unidade nacional, independente de raças" (DAMASCENO, 1988, p. 63).

Conforme Benedita Gouveia Damasceno (1988) e Zilá Bernd (1987), a designação Literatura Negra não deve ser apontada pela etnia, atributo que não seria primordial de tal literatura. Por sua vez, Álvaro Hattnher (2009) defende que é difícil que um autor branco reconheça uma identidade negra, isto é, retenha um sentimento de exaltação a respeito da cultura negra. Nessa perspectiva, justifica que a Literatura Negra é a estabelecida por autores/as negros/as com um ponto de vista e experiência histórica de negro/a. Segundo Hattnher (2009), Literatura Negra é a experiência negra transcrita, posto que ela se apresenta através dos vocábulos, ícones e símbolos incluídos no texto literário. A Literatura Negra reflete a expressividade inventiva dos/as autores/as negros/as e, além de enobrecer a identidade, ela é, sobretudo, uma produção que se opõe ao preconceito racial.

Sob certo ponto de vista, tal confirmação do autor destaca uma acepção positiva, à proporção que consente ao brasileiro reconectar-se com elementos da sua história que lhe tem sido negada. Dessa forma, valoriza-se o reconhecimento de que os brasileiros receberam forte influência africana, independentemente de sua origem étnico-racial.

Narrar a história de uma nação é determinar sua identidade. Para Bernd (2003, p. 17), “a construção da identidade é indissociável da narrativa e consequentemente da literatura". Entende-se que o discurso da Literatura Negra é o discurso da identidade, o discurso que ambiciona a desconstrução e a reconstrução identitária inclusa neste sistema de sentidos, empregando como questão crucial a análise da noção de identidade nacional uniforme e homogênea. É notório que a segregação subalterniza o negro na construção 
da identidade, suprimindo-o da participação ativa na memória nacional. Destarte, julgamos que a Literatura Negro-brasileira:

[...] nasce na e da população negra que se formou fora da África, e de sua experiência no Brasil. A singularidade é negra e, simultaneamente, brasileira, pois a palavra negro aponta para um processo de luta participativa nos destinos da nação e não se presta ao reducionismo contribucionista a uma pretensa brancura que a englobaria como um todo a receber, daqui e dali, elementos negros e indígenas para se fortalecer. Por se tratar de participação na vida nacional, o realce a essa vertente literária deve estar referenciado à sua gênese social ativa. $\mathrm{O}$ que há de manifestação reivindicatória apoia-se na palavra "negra". (CUTI, 2010, p. 44-45)

Conceição Evaristo também contribui para a reflexão sobre os traços dessa literatura. A autora apresenta elementos que estabelecem a Literatura Afro-Brasileira e a distinguem da Literatura Brasileira:

\begin{abstract}
Considero como elementos constitutivos de um discurso literário afrobrasileiro: a afirmação de um pertencimento étnico; a busca e a valorização de uma ancestralidade africana, que pode ser revelada na própria linguagem do texto, na estética do texto; a intenção de construir um contradiscurso literário a uma literatura que estereotipiza o negro; a cobrança da reescrita da História brasileira no que tange à saga dos africanos e seus descendentes no Brasil; a enfática denúncia contra o racismo e as injustiças sociais que pesam sobre o negro na sociedade brasileira. E agora apresento um elemento vital na constituição de uma literatura afro-brasileira - a autoria [...]. (EVARISTO, 2011 apud DUARTE; FONSECA, 2011, p. 114)
\end{abstract}

Temos, no percurso histórico, autores precursores que realizaram publicações nos séculos XVIII e XIX, e que não estão marcados ainda pelas questões contemporâneas; o foco principal era a extinção da escravidão. E, como já mencionado, autores/as do século XIX, como Machado de Assis, Maria Firmina dos Reis e tantos/as outros/as autores/as, que precisavam ter muito mais cautela ao escrever um discurso de protesto. A indignação perante o absurdo que era a escravidão deveria ser pautada com certa sutileza, pois o público leitor, em geral, era senhor de escravo.

A Literatura Afro-Brasileira ou Negra, cuja autoria negra conserva um empenho e engajamento com a etnicidade afrodescendente, surgiu com as produções de determinados escritores, como Luís Gama (1830-1882), fillho de um aristocrático português e de uma africana. Foi o pioneiro a dedicar versos de amor a uma mulher negra. Ressalta-se, ainda, o mulato Lima Barreto (1881-1922), com a obra Clara dos Anjos (1922). Menciona-se, também, Lino Guedes (1897-1951), escritor de O canto do cisne 
preto (1926), Urucungo (1936) e Negro preto corda noite (1936), cuja poética é "marcadamente irônica, com alguma dose de autocomplacência e apelos de afirmação racial bem comportados" (PROENÇA FILHO, 2004, p. 14-15). E nesse conjunto distinto masculino figura, ainda, Maria Firmina dos Reis (1825-1917), com a obra abolicionista Úrsula (1859), estimada a primeira narrativa da literatura afro-brasileira, que "tematiza o assunto negro a partir de um ponto de vista interno e comprometido politicamente em recuperar e narrar a condição do ser negro em nosso país" (DUARTE, 2004b, p. 279).

Os textos dos/as autores/as anteriormente mencionados/as se harmonizam na escrita empenhada com a etnicidade afrodescendente, em que as marcas de etnia, classe ou de gênero frequentemente não se ajustam às características da Literatura canônica, de particularidades principalmente eurocêntricas. Acredita-se que para o/a escritor/a integrar a Literatura Afro-Brasileira, preocupado/a com a temática negra, precisará comprometer-se com as questões relativas ao povo negro, sobretudo no Brasil. Desse modo, integrar esse empenho étnico à vivência desse/a escritor/a pressupõe-se como condição basilar para que, em sua escrita, seja analisado tal engajamento. Todavia, quanto à escrita direcionada para os paradigmas dessa literatura, pode-se categorizála mediante duas perspectivas: a do não negro, intitulado de negrismo, e a do olhar negro, chamado de negritude. Daniela de Oliveira Barbosa Guedes (2005, p. 627-628) caracteriza visivelmente essas terminologias:

\footnotetext{
O negrismo possui elementos em comum com a vanguarda europeia, que busca o primitivismo africano, apenas para a descrição do negro, do que este possui de exótico, da mitologia de sua sensualidade e também o ambiente e os sons negros, como uma fonte de temas e formas. O texto negrista é um discurso produzido por uma elite branca, ou pelo menos de visão branca, que incorpora a temática negra. Este tipo de texto não se fundamenta na procura e/ou na afirmação da identidade negra, estas são características peculiares à negritude. Nesta perspectiva é que o negro, a partir de seu olhar de dominado, de oprimido, percebendo e desejando a mudança de sua condição na sociedade, torna-se apto a produzir uma arte denominada literatura afro-brasileira. (GUEDES, 2005, p. 627-628)
}

Por certo, a partir do século XX, ampliou-se a quantidade de pesquisadores que tratam da presença de uma vertente negra na Literatura Brasileira. É no século XIX que a Literatura Afro-brasileira conquista uma abrangência de leitores, por meio da poesia de Castro Alves e, sobretudo, do texto literário produzido por Luís Gama. Castro Alves inseria em seus textos a temática dos escravos no período de ebulição político- 
abolicionista, escrevendo poesias eloquentes, de forma que foi naturalmente inserido no cânone. Já Luís Gama suportou a estigmatização da cor. É considerado o precursor da Literatura Afro-Brasileira por teóricos como Zilá Bernd, Domício Proença Filho, entre outros. Conforme Heloisa Toller Gomes (1994):

O discurso literário brasileiro, no século XIX, foi impregnado pela ideologia social vigente [...]. Na verdade, poucos escritores abolicionistas foram capazes de ir além da ideologia racial da época, e de transcender os interesses de classe, os quais, conforme se sabe, moldaram a forma como se extirpou a escravidão não só no Brasil, mas na maior parte das Américas. (GOMES, 1994, p. 389)

Afirma-se que a literatura nacional brasileira aparece permeada de estereótipos ultrajantes sobre o sujeito negro. Na Literatura Brasileira, percebe-se a bastardia do negro, posto que esse é exposto e caracterizado como exótico, no tocante ao seu porte físico ou ao enaltecimento sexual da mulher negra:

\footnotetext{
a imagem da linda mulata, numa sociedade como a colonial, em que a mulher era rara, é menos uma glorificação da cor negra do que uma glorificação da cor branca: a mulata era escolhida porque se aproximava mais da europeia do que da africana. (BASTIDE, 1992, p. 115)
}

Assim sendo, a Literatura Afro-brasileira se designa, atualmente, pelo agrupamento de textos de literatos afrodescendentes comprometidos com a estruturação de uma poética negra, e se volta ao período colonial porque a afirmação desta identidade cultural se atribui, em parte, ao empenho de resgate efetivado por pesquisadores da área. Assim, segundo Duarte (2007), o romance Ponciá Vicêncio (2003), de Conceição Evaristo:

\begin{abstract}
Se entendido como texto de autoria afrodescendente, tratando de tema vinculado à presença desse segmento nas relações sociais vividas no país, a partir de uma perspectiva identificada politicamente com as demandas e com o universo cultural afro-brasileiro e destacando ainda o protagonismo negro nas ações, em especial aquelas em que se defrontam com o poder e com seus donos, não há dúvida de que Ponciá Vicêncio não só preenche tais requisitos, como ocupa o lugar supostamente vazio do romance afro-brasileiro. (DUARTE, 2007, p. 27)
\end{abstract}

Desse modo, a narrativa citada pelo autor compreende uma narrativa escrita por uma mulher negra, com personagens negros, na qual se debatem temáticas referentes ao negro e, sobretudo, à condição da mulher negra subalternizada no panorama brasileiro. 
Gayatri Spivak, teórica indiana, em Pode o subalterno falar? (2010), salienta que a mulher negra possui uma dupla subalternidade, referindo-se a uma coletividade subalterna. Todavia, o que constitui isso é uma voz que não pode ser ouvida, isto é:

as camadas mais baixas da sociedade, constituídas pelos modos específicos de exclusão dos mercados, da representação política e legal e da possibilidade de se tornarem membros plenos no estrato social dominante. (SPIVAK, 2010, p. 12)

Essa definição compreende que todo sujeito que não conquista representação na sociedade é subalterno, destarte, o subalterno precisa indispensavelmente de quem o represente, em virtude de sua condição submissa.

Se a fala do subalterno é anulada, a mulher subalterna se situa em um posicionamento fronteiriço, devido às dificuldades implícitas às questões de gênero, visto que "se no contexto da produção colonial, o sujeito subalterno não tem história e não pode falar, o sujeito subalterno feminino está ainda mais profundamente na obscuridade" (SPIVAK, 2010, p. 82).

Ainda a respeito da fala do subalterno, e sobre as condições em que o indivíduo possa ter sua voz ouvida, Gayatri Spivak (2010) acentua que:

Para o "verdadeiro" grupo subalterno, cuja identidade é a sua diferença, podese asseverar que não há nenhum sujeito subalterno irrepresentável que possa saber e falar por si mesmo. A solução do intelectual não é a de se abster da representação. O problema é que o itinerário do sujeito não foi traçado de maneira a oferecer um objeto de sedução ao intelectual representante. (SPIVAK, 2010, p. 60)

O subalterno é privado de voz, sendo um indivíduo sem fala, sem presença, excluído pela violência neocolonial. Spivak (2010) argumenta que seja proporcionada uma tomada de voz para esses sujeitos excluídos, a fim de que consigam, por conseguinte, adquirir a consciência a respeito de suas experiências, sendo capazes de apresentá-las, em um processo de afirmação de suas identidades, deslocamento e mudança de fronteiras.

É importante ressaltar que, na obra em estudo, o negro representa um sujeito fraturado e deixa de ser objeto, deixa de ser apenas temática, e passa a ser autor, encarando o mundo sob uma perspectiva coletiva e, ao mesmo tempo, particular: "Foi o branco que criou o negro" e que os negros, ao se autoproclamarem como tal, querem conscientemente 
“criar a si mesmos" (LOBO, 2007, p. 326); buscam uma autorrepresentação e fazer abordagens sobre si próprios.

Assim, em virtude do exposto, notamos que a Literatura Afro-Brasileira intenciona atender à demanda histórica de um povo reprimido, embora combativo e resistente. Consideramos que são insuficientes as discussões sobre o universo afrobrasileiro e as distintas temáticas que esse universo abrange, bem como as críticas literárias disponíveis. Por fim, há que se reconhecer a existência de uma expressão literária afro-brasileira, presente em nossa sociedade desde a sua formação.

\section{Referências}

ASSIS, Joaquim Maria Machado de. Obra Completa: v. 1 (Romance). Rio de Janeiro: Ed. Nova Aguilar, 1994.

BASTIDE, Roger. Estereótipos de negros através da Literatura Brasileira. In: Estudos afro-brasileiros. São Paulo: Perspectiva, 1992.

BERND, Zilá. Depoimento. In: DUARTE, Eduardo de Assis (Org.). Literatura $e$ Afrodescendência no Brasil: antologia crítica. Belo Horizonte: Editora UFMG, 2011. p. 148-157.

Enraizamento e errância: duas faces da questão identitária. In: SCARPELLI, Marli Fantini; DUARTE, Eduardo de Assis (Org.). Poéticas da diversidade. Belo Horizonte: UFGM/FALE: Pós-Lit, 2002.

Literatura negra. In: JOBIM, J. L. (Org.). As palavras da crítica. Rio de Janeiro: Imago, 1992. p. 267-276.

. Negritude e Literatura na América Latina. Porto Alegre: Mercado Aberto, 1987. 2003 .

Literatura e Identidade Nacional. Porto Alegre: Ed. da Universidade/UFRGS, O que é Negritude. São Paulo: Brasiliense, 1988a.

Introdução à Literatura Negra. São Paulo: Brasiliense, 1988 b.

CUTI, Luiz Silva. Literatura negro-brasileira. São Paulo: Selo Negro, 2010.

Depoimento. In: DUARTE, Eduardo de Assis (Org.). Literatura $e$ Afrodescendência no Brasil: antologia crítica. Belo Horizonte: Editora UFMG, 2011. p. 45-70. 
DAMASCENO, Benedita Gouveia. Poesia negra no Modernismo brasileiro. Campinas: Pontes, 1988.

DUARTE, Constância Lima. Gênero e violência na literatura afro-brasileira. In: ALEXANDRE, Marcos Antônio; DUARTE, Constância Lima; DUARTE, Eduardo de Assis (Org.). Falas do outro: literatura, gênero, etnicidade. Belo Horizonte: Nandyala; NEIA, 2010. p. 229-234.

DUARTE, Eduardo de Assis. O Bildungsroman afro-brasileiro de Conceição Evaristo. In: ALEXANDRE, Marcos Antônio (Org.). Representações performáticas brasileiras: teorias, práticas e suas interfaces. Belo Horizonte: Mazza Edições, 2007. p. 22-29.

Literatura afro-brasileira: 100 autores do século XVIII ao XX. Rio de Janeiro: Pallas, 2004a.

Literatura, política, identidades. Belo Horizonte: UFMG, 2005.

; CAMPOS, Maria Consuelo Cunha. Conceição Evaristo. In: ; FONSECA, Maria Nazareth Soares (Org.). Literatura e afrodescendência no Brasil: antologia crítica. v. 2, Consolidação. Belo Horizonte: UFMG, 2011. p. 207-226.

Por um conceito de literatura afro-brasileira. Terceira margem, Rio de Janeiro, n. 23, p. 113-138, jul./dez. 2010.

Literatura Afro-Brasileira: um conceito em construção. Estudos de Literatura Brasileira Contemporânea, Brasília, n. 31, p. 11- 23, jan./jun. 2008.

Maria Firmina dos Reis e os primórdios da ficção afro-brasileira. In: REIS, Maria Firmina dos. Úrsula. 4. ed. Organização, atualização e posfácio de Eduardo de Assis Duarte. Florianópolis: Ed. Mulheres; Belo Horizonte: Ed. PUC Minas, 2004b. p. 265281.

DOMINGUES, Petrônio. Movimento da negritude. Uma breve reconstrução histórica. Mediações - Revista de Ciências Sociais. Londrina, v. 10, n. 1, p. 25-40, jan./jun. 2005. Disponível

em: http://www.uel.br/revistas/uel/index.php/mediacoes/article/viewFile/2137/2707. Acesso em: 21 jun. 2016.

EVARISTO, Conceição. Depoimento. In: DUARTE, Eduardo de Assis; FONSECA, Maria Nazareth Soares. Literatura e afrodescendência no Brasil: antologia crítica. v. 4. Belo Horizonte: Editora UFMG, 2011. p. 103-116.

FANON, Frantz. Pele Negra, Máscaras Brancas. Tradução de Renato da Silveira. Salvador: EDUFBA, 2008.

FONSECA, Maria Nazareth Soares. Literatura Negra os sentidos e as ramificações. In: DUARTE, Eduardo de Assis (Org.). Literatura e Afrodescendência no Brasil: antologia crítica. v. 4. 2011. Belo Horizonte: Editora UFMG. p. 245-277. 
FREIRE, Manoel. A motivação autobiográfica em Lima Barreto. Manuscrítica - Revista de Crítica, São Paulo, n. 26, p. 86-96, jun. 2014. Disponível em: http://revistas.fflch.usp.br/manuscritica/article/view/2096. Acesso em: 04 jul. 2016.

FREIRE, Paulo. Pedagogia do oprimido. Rio de Janeiro: Paz e Terra, 2005.

GAMA, Luiz. Primeiras Trovas Burlescas. São Paulo: Martins Fontes, 2000.

GOMES, Heloísa Toller. As marcas da escravidão: o negro e o discurso oitocentista no Brasil e nos Estados Unidos. Rio de Janeiro: Editora UFRJ, 1994.

GUEDES, Daniela de Oliveira Barbosa. Negrismo e negritude: a mulher negra na poesia de Jorge de Lima e Solano Trindade. In: SEMINÁRIO NACIONAL MULHER E LITERATURA E SEMINÁRIO INTERNACIONAL MULHER E LITERATURA, XI e II, 2005. Anais...RJ: UERJ/ANPOLL, 2005. Meio digital (CD-ROM).

HATTNHER, Álvaro. A poesia negra na literatura afro-brasileira: exercícios de definição e algumas possibilidades de investigação. Terra Roxa e Outras Terras - Revista de Estudos Literários, v. 17, dez. 2009

IANNI, Octávio. Literatura e consciência. Revista do Instituto de Estudos Brasileiros, São Paulo. Edição Comemorativa do Centenário da Abolição da Escravatura, n. 28, 1988.

LIEBIG, Sueli Meira. Dossiê Black \& branco: Literatura, racismo e opressão nos Estados Unidos e no Brasil. João Pessoa: Ideia, 2003.

LOBO, Luiza Leite Bruno. Crítica sem juízo. 2. ed. Rio de Janeiro: Garamond, 2007.

LOPES, Nei. Dicionário afro-brasileiro. Santo André: Selo Negro, 2006.

MACEDO, Joaquim Manoel de. As Vítimas Algozes: quadros da escravidão. Parte III: Lucinda, a mucama. São Paulo: Martin Claret, 2010.

MUNANGA, Kabengele. Negritude: usos e sentidos. 3. ed. Belo Horizonte: Autêntica Editora, 2012.

NASCIMENTO, Abdias. Depoimento. In: DUARTE, Eduardo de Assis (Org.). Literatura e Afrodescendência no Brasil: antologia crítica. Belo Horizonte: Editora UFMG, 2011. p. 13-27.

PROENÇA FILHO, Domício. A trajetória do negro na literatura brasileira. Estudos avançados, v. 18 n. 50, São Paulo, jan./abr. 2004. Disponível em: http://www.scielo.br/scielo.php?script=sci_arttext\&pid=S0103-40142004000100017. Acesso em: 29 maio 2016.

SOUZA, Neusa Santos. Tornar-se Negro. Rio de Janeiro: Graal, 1983. 
SOUZA, Florentina da Silva. Afrodescendência em Cadernos Negros e Jornal do MNU. Belo Horizonte: Autêntica, 2005.

SCHMIDT, Rita Teresinha. Cânone e contra-cânone: nem aquele que é o mesmo nem este que é o outro. In: CARVALHAL, Tânia Franco (Org.). O discurso crítico na América Latina. Porto Alegre: IEL; Editora da Unisinos, 1996. p. 11-21.

SPIVAK, Gayatri Chakravorty. Pode o Subalterno Falar? Tradução de Sandra Regina Goulart de Almeida et al. Belo Horizonte: Editora UFMG, 2010.

Recebido em: 28/05/2021

Aceito em: 21/07/2021

\footnotetext{
${ }^{1}$ No campo do discurso político abolicionista o negro era frequentemente considerado como um símbolo, e não em sua grandeza humana. O pensamento era findar a escravidão e razões econômicas também faziam parte, além da coerção oriunda de outros países.

${ }^{2}$ Os autores citados apresentavam uma postura puramente negrista em relação ao negro e a sua cultura: "o negrismo, enquanto manifestação especificamente literária, pouco tem a ver com a negritude, termo que engloba aqueles movimentos, surgidos nos anos 30, que reivindicam os direitos dos negros. [...] A busca do exotismo, a introdução de uma estética baseada na plástica dos fetiches africanos ou das máscaras polinésias e o retorno aos elementos primitivos da cultura. [...] Trata-se de um discurso plástico produzido por uma elite artística branca e europeia que incorpora uma temática negra para divulgá-la junto a um público também branco" (DUARTE, 2005, p. 579-580).

${ }^{3}$ Site de Literatura afro-brasileira, com textos e biografias de autores/as, além de artigos críticos sobre os/as mesmos/as. Disponível em: http://www.letras.ufmg.br/literafro. Acesso em: 24 maio 2021.

${ }^{4}$ Vocábulo generalizado.

${ }^{5}$ A expressão em evidência faz menção a rótulos e anúncios publicitários propagados por volta de 1915 , para uma farinha de banana, em que a imagem apresentava o rosto de um soldado da infantaria senegalês com traje do batalhão colonial e estampando um sorriso, posteriormente denunciado por Léopold Senghor como um sorriso estereotipado que dava um ar idiota à personagem, fortalecendo o preconceito generalizado. Tal sorriso, que ficou conhecido como "sorriso banana", foi utilizado em vários anúncios nos anos 1980.
} 